Journal of Physical Science, Vol. 29(Supp. 2), 53-62, 2018

\title{
Production of Liquid Oil from Thermolysis of Electrical and Electronic Wastes (E-waste) under Microwave Irradiation
}

\author{
Samsudin Anis, ${ }^{*}$ Suprayoga Edi Lestari, Wahyudi and Karnowo \\ Department of Mechanical Engineering, Universitas Negeri Semarang, Kampus Sekaran, \\ Gunungpati, Semarang 50229 Indonesia
}

*Corresponding author: samsudin_anis@mail.unnes.ac.id

Published online: 30 July 2018

To cite this article: Anis, S. et al. (2018). Production of liquid-oil from thermolysis of electrical and electronic wastes (e-waste) under microwave irradiation. J. Phys. Sci., 29(Supp. 2), 53-62, https://doi.org/10.21315/jps2018.29.s2.5

To link to this article: https://doi.org/10.21315/jps2018.29.s2.5

\begin{abstract}
A preliminary study of thermolysis for producing liquid oil from electrical and electronic wastes (e-waste) has been carried out. Various efforts have been made to improve thermolysis process in order to obtain higher yield of liquid oil. The research aims to investigate the effect of temperature and types of e-waste on the yield of liquid oil. A domestic microwave oven was modified and used to produce liquid oil. It was connected with standard condensation unit with water circulating system. Three types of e-waste samples (computer or laptop case, hand phone case and electrical cables/wires) were employed. About $150 \mathrm{~g}$ of each samples was thermolysed at $350^{\circ} \mathrm{C}, 400^{\circ} \mathrm{C}$ and $450^{\circ} \mathrm{C}$ under nitrogen flow of 0.3 LPM using activated carbon as an absorber and a microwave power of $900 \mathrm{~W}$. The samples were characterised using TGA and ultimate analyser whereas heating value of the optimum liquid product was analysed using bomb calorimeter. This study showed that thermolysis temperature and type of e-waste affect yield of liquid oil. Maximum yields of liquid oil were obtained at $450^{\circ} \mathrm{C}$ for hand phone case, $400^{\circ} \mathrm{C}$ for computer case and at $350^{\circ} \mathrm{C}$ for electrical cables. Among the e-waste studied, hand phone case provided the highest liquid oil yield of $56.2 \mathrm{wt} \%$.
\end{abstract}

Keywords: Thermolysis, electronic waste, e-waste, microwave irradiation, liquid oil

\section{INTRODUCTION}

Nowadays, the production capacity of electric and electronic equipment in the world has significantly increased due to the high demand of the products along with the socio-economic growth. In addition, it was also triggered by shorter duration

(C) Penerbit Universiti Sains Malaysia, 2018. This work is licensed under the terms of the Creative Commons Attribution (CC BY) (http://creativecommons.org/licenses/by/4.0/). 
of electronic product usage. In Asia, Indonesia is among the largest consumers of electronics equipment, which can be seen from the high production of electric and electronic devices. In 2007, Indonesia produced more than 3 billion units of household electronic appliances and IT equipment, 4.3 million units of television, 2.1 million units of refrigerator and 900,000 units of air-conditioning and washing machines, respectively. ${ }^{1}$ Based on the data from Indonesian Cellular Telephone Association, there were approximately 340 million mobile phone users in 2015 . The large number of the products clearly contributed to the high volume of electric and electronic wastes (e-waste).

According to United Nations Environment Programme (UNEP) report, generation of e-waste reaches 40 million tons per year. ${ }^{2}$ This number is predicted to increase continuously in the future. Electronic plastic waste becomes one of the highest volumes of solid waste. In EU countries, the growth of electronic plastic waste increased three times faster than the average of municipal solid waste. The high amount of e-waste not only occurred in developed countries, but also in developing countries including Indonesia.

Plastics from e-waste have become a serious environmental problem as they generally contain toxic and fire-resistant halogens. These plastics are carcinogenic because of the formation of polybrominated dibenzo dioxins/furans during the production process of the plastics. In Vietnam, there was accumulation of polychlorinated biphenyls and brominated flame retardants in breast milk from women living in e-waste recycling sites. ${ }^{3}$

Although e-waste is harmful to the environment and health, it contains various precious metals such as copper, iron, gold, silver, etc. ${ }^{4} \mathrm{E}$-waste also has the potential to be processed into other products because it contains a number of hydrocarbon materials such as plastics and rubber. ${ }^{5}$ For this purpose, some literature works indicated that e-waste can be converted into liquid oil through pyrolysis process. ${ }^{5-7}$ In general, the pyrolysis process is carried out using a conventional reactor in which the heat transfer process is very limited. This has an impact on the low yield of liquid oil. ${ }^{8,9}$

In this research, pyrolysis/thermolysis of e-waste was done using microwave technology. This technology has been proven to overcome the limitations of conventional technology due to the rapid heating process of materials. ${ }^{9-11}$ This is certainly beneficial because temperature is one of the main factors affecting the yield of the products in pyrolysis processes. Although research on e-waste pyrolysis using microwave energy has been done, the available information is still limited. ${ }^{10,12}$ Previous studies focused on the processing of e-waste from printed 
circuit boards (PCBs) that contain a lot of metals. This paper emphasises on the processing of plastic materials obtained from three types of e-waste, i.e., computer case, hand phone case and electrical cables/wires. Therefore, this research aims to investigate the effect of temperature and types of e-waste on the yield of liquid oil with the aid of microwave irradiation.

\section{EXPERIMENTAL}

\subsection{Materials}

E-waste from computer case, hand phone case and electrical cable were collected from several local landfills. Prior to use, the plastic parts were separated from the metal components of the raw material and then shredded into small pieces with an average size of about 5-15 mm. Activated carbon powder was used as an absorber material to increase the reactor temperature.

Proximate and ultimate analysis of e-waste were performed to evaluate their physical and chemical properties. Proximate analysis was conducted by using a Perkin Elmer Pyris 1 thermo gravimetric analyser (TGA) while ultimate analysis was carried out by using a Perkin Elmer 2400 Series II CHNS/O elemental analyser.

\subsection{Experimental Apparatus}

A schematic diagram of the experimental apparatus is presented in Figure 1. It consists of two main units: microwave reactor and cooling system. Microwave reactor includes a modified microwave oven and a ceramic reactor. The modified microwave oven has a frequency of $2.45 \mathrm{GHz}$ with a capacity of 231 . The maximum output power of the microwave oven is $900 \mathrm{~W}$. A temperature detector was also attached to monitor microwave cavity temperature. A ceramic reactor with $120 \mathrm{~mm}$ internal diameter (ID) and $140 \mathrm{~mm}$ length was used and designed as a fixed bed reactor. It contains a K-type thermocouple at the centre of the reactor. Cooling system consists of a double pipe glass condenser and a liquid collector of $250 \mathrm{ml}$ glass bottle. To transport volatile material from ceramic reactor to condenser, stainless steel pipe with a size of 0.5 in ID was used. 


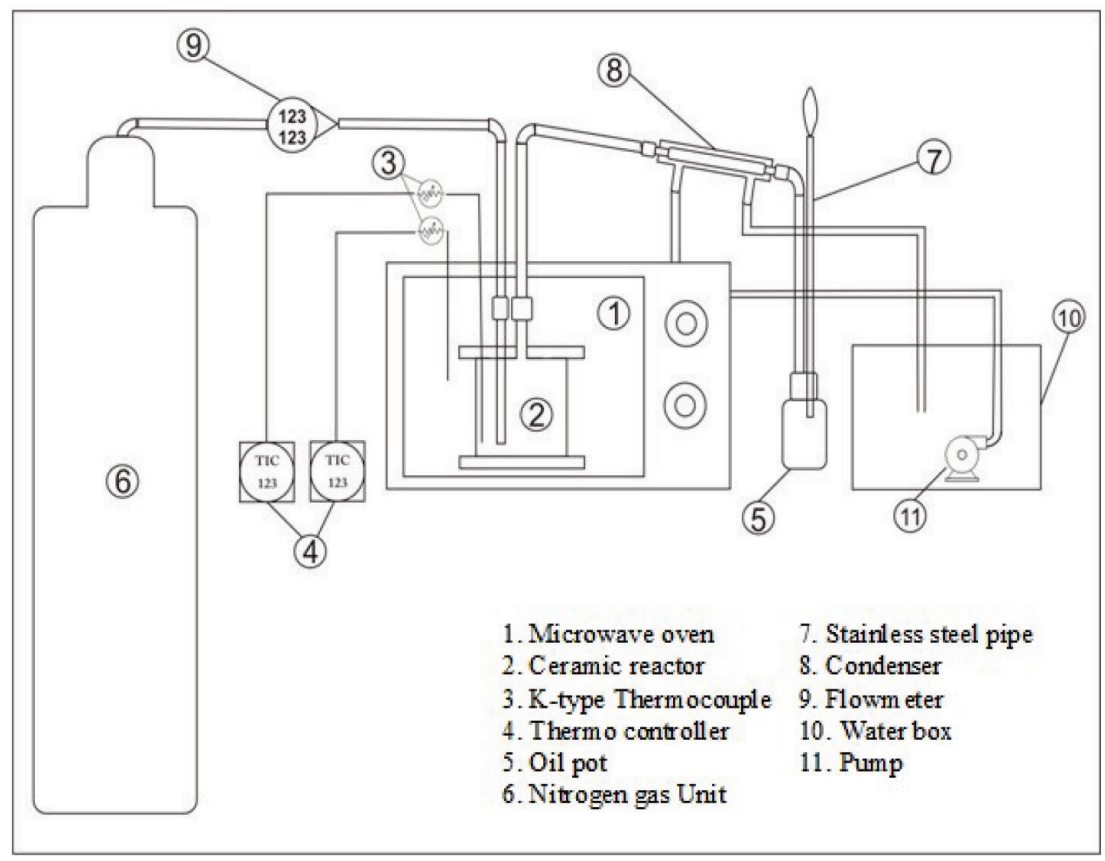

Figure 1: Schematic diagram of the experimental apparatus.

\subsection{Pyrolysis Experiments}

Before starting and during each experiment, pure nitrogen gas was supplied at 0.3 LPM to ensure inert environment within the reactor and other equipment and to sweep the pyrolysis vapour product from the reactor to the condenser. All experiments were performed using a microwave power of $900 \mathrm{~W}$. The total amount of e-waste and activated carbon in the reactor was kept constant at $300 \mathrm{~g}$ with a ratio of $1: 1$. Pyrolysis processes were carried out at various temperatures of $350^{\circ} \mathrm{C}$, $400^{\circ} \mathrm{C}$ and $450^{\circ} \mathrm{C}$ using three types of e-waste including computer case, hand phone case and electrical cable. After each experiment, the amount of char and liquid oil were weighed to obtain the yields of products, while the gases product was determined by the difference. Based on the obtained data, the optimum yield of liquid oil was then subjected to heating value measurement using a Bomb Calorimeter. Three samples were taken to obtain the average. 


\section{RESULTS AND DISCUSSION}

\subsection{E-waste Characterisation}

The e-waste samples used in this study were plastic materials separated from the metal parts. Plastic is the result of polymerisation that is a combination of monomers to form long chains. The types of plastic are very diverse, including plastic from e-waste. Tables 1 and 2 show the results of elemental and proximate analyses of the samples, respectively. The result of elemental analysis showed that carbon and hydrogen were found to be the main constituent elements of the samples. Among the samples, the highest carbon and hydrogen contents were obtained in computer case while the lowest were in electrical cable sample. In addition, nitrogen and sulphur were also found in the tested samples, in which the computer case has also the highest content. It shows that computer case is generally produced from acrylonitrile butadiene styrene (ABS) material. ${ }^{13}$ Meanwhile, the hand phone case sample did not contain any nitrogen, indicating it was composed of polymeric materials such as polycarbonate. ${ }^{6}$

Table 1: Elemental composition of e-waste (wt $\%)$.

\begin{tabular}{lcccc}
\hline Sample & $\mathrm{C}$ & $\mathrm{H}$ & $\mathrm{N}$ & $\mathrm{S}$ \\
\hline Electrical cables & 42.69 & 3.38 & 0.47 & 0.16 \\
Computer case & 88.14 & 6.68 & 3.11 & 0.34 \\
Hand phone case & 80.34 & 4.99 & 0.00 & 0.14 \\
\hline
\end{tabular}

Table 2: Proximate analysis of e-waste (wt $\%)$.

\begin{tabular}{lcccc}
\hline Sample & Moisture content & Volatile matter & Fixed carbon & Ash \\
\hline Electrical cables & 0.127 & 70.888 & 7.366 & 21.619 \\
Computer case & 0.942 & 97.076 & 2.43 & 0.448 \\
Hand phone case & 0.618 & 91.153 & 7.901 & 0.328 \\
\hline
\end{tabular}

Other important characteristics of the e-waste are volatile matter, fixed carbon, ash and moisture contents, as given in Table 2. As shown, all samples have high volatile matter contents. Plastics from computer and hand phone cases contain more than $90 \%$ volatile organic matter, reflecting a high potential to be converted into liquid oil and gas fuels. On the other hand, high content of inorganic material including ash was found in the electrical cable. It shows that plastics from electrical cable are normally made from polyvinyl chloride (PVC). Based on the report by British Plastics Federation, PVC is manufactured from the mixture of 57\% chlorine and $43 \%$ carbon which makes PVC an excellent fire resistance, thus very suitable for 
electrical insulation. ${ }^{14}$ Its relatively low carbon content is confirmed also in this study as shown in Table 1.

\subsection{Yield of Products}

The yields of products, i.e., solids, liquids and gases obtained from thermolysis of electrical cable, computer case and hand phone case under microwave energy are presented in Figures 2, 3 and 4, respectively. The figures provide information related to the effect of temperature from $350^{\circ} \mathrm{C}$ up to $450^{\circ} \mathrm{C}$ on the decomposition process of the employed e-waste.

Figure 2 shows the yields of products at three different temperatures during thermal decomposition of electrical cable. As indicated in the figure, the yields of product were insignificantly influenced by the temperature. The main product in these samples was solid for all reactor temperatures investigated, occupying about 71 $\mathrm{wt} \%$ on average. On the other hand, the highest yields of liquid and gas products were obtained at temperatures of $350^{\circ} \mathrm{C}$ and $450^{\circ} \mathrm{C}$, respectively. These results indicated that electrical cable is mainly composed of inorganic material such as chlorine and ash, as presented in Table $2 .{ }^{14}$ The low yield of liquid oil suggested that plastics from electrical cables require pre-treatment process to remove chlorine before thermal decomposition to obtain more liquid oil as an alternative fuel. ${ }^{15}$

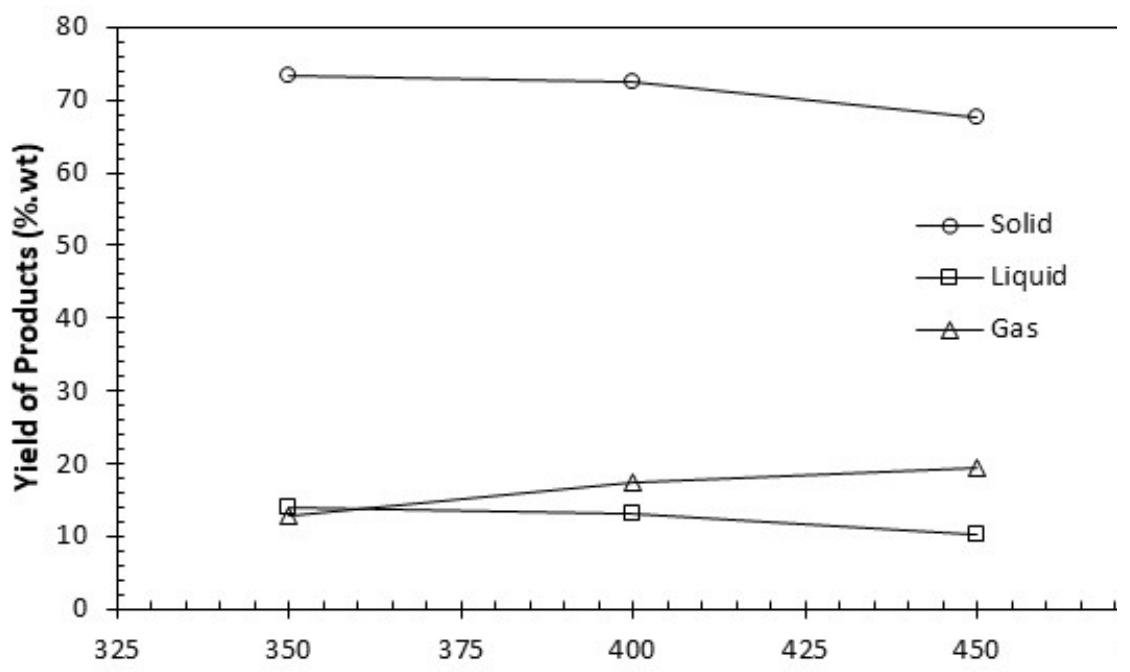

Figure 2: Product yield of electrical cable as a function of temperature. 
Figure 3 presents the yields of products from thermolysis of computer case as a function of temperature. As shown, the yield of solid product tended to decrease with the increase of temperature. On the contrary, gas product increased considerably especially at the highest applied temperature of $450^{\circ} \mathrm{C}$. Different result was found for liquid oil product, in which the optimum yield was obtained at middle temperature of $400^{\circ} \mathrm{C}$. This confirmed that rapid decomposition process of plastics from computer case (generally fabricated from ABS polymer) under microwave heating could be expected at $400^{\circ} \mathrm{C}$. The obtained result is different from previous study where the optimum yield of liquid oil is obtained at a relatively high temperature of $600^{\circ} \mathrm{C} .{ }^{16}$ This difference is possible because of the different heating systems applied.

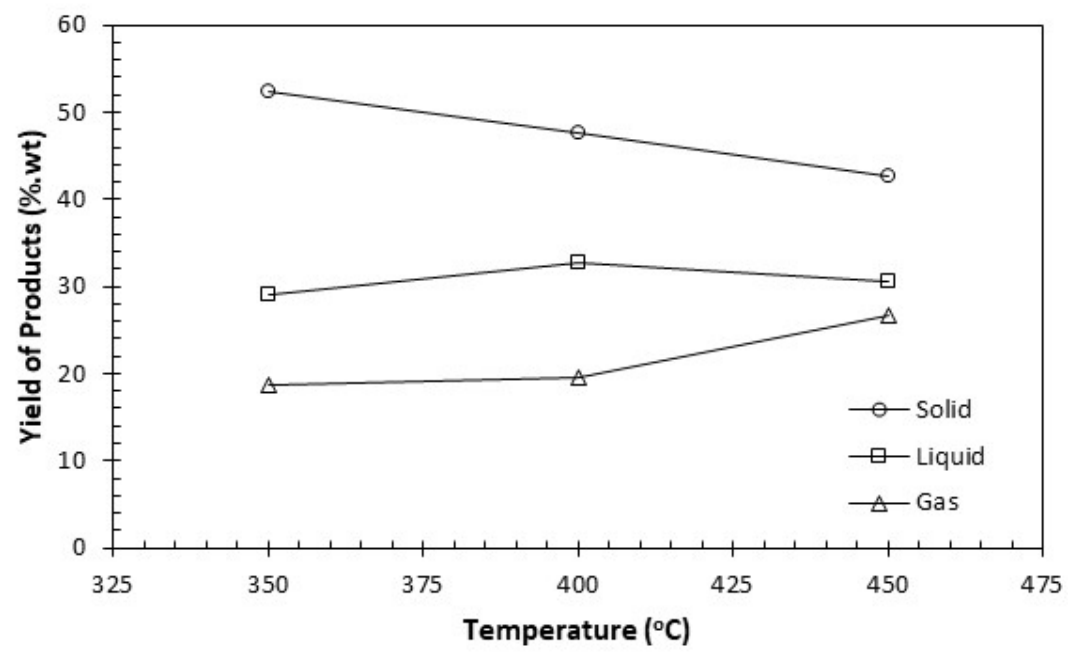

Figure 3: Product yield of computer case as a function of temperature.

Figure 4 shows the yields of products from thermolysis of hand phone case as a function of temperature. It can be observed from the figure that the yield of solid product decreased significantly with the increase of temperature. On the contrary, gas and liquid products increased considerably as the temperature increased. A particular attention should be given to the highly significant yield of liquid oil product which can reach more than $55 \mathrm{wt} \%$ at $450^{\circ} \mathrm{C}$. This obtained result is in line with a previous study by de Marco et al..$^{5}$ The liquid oils obtained in the thermolysis process were a complex mixture of organic compounds. Study by Hall and Williams reported that the largest component of the liquid oil from mixed wastes of electrical and electronic equipment (WEEE) was phenol, 4-isopropylphenol and styrene. ${ }^{16}$ The high concentration of phenol and phenol derivatives in liquid oil might be from polycarbonate as the main constituent of hand phone case. ${ }^{5}$ 


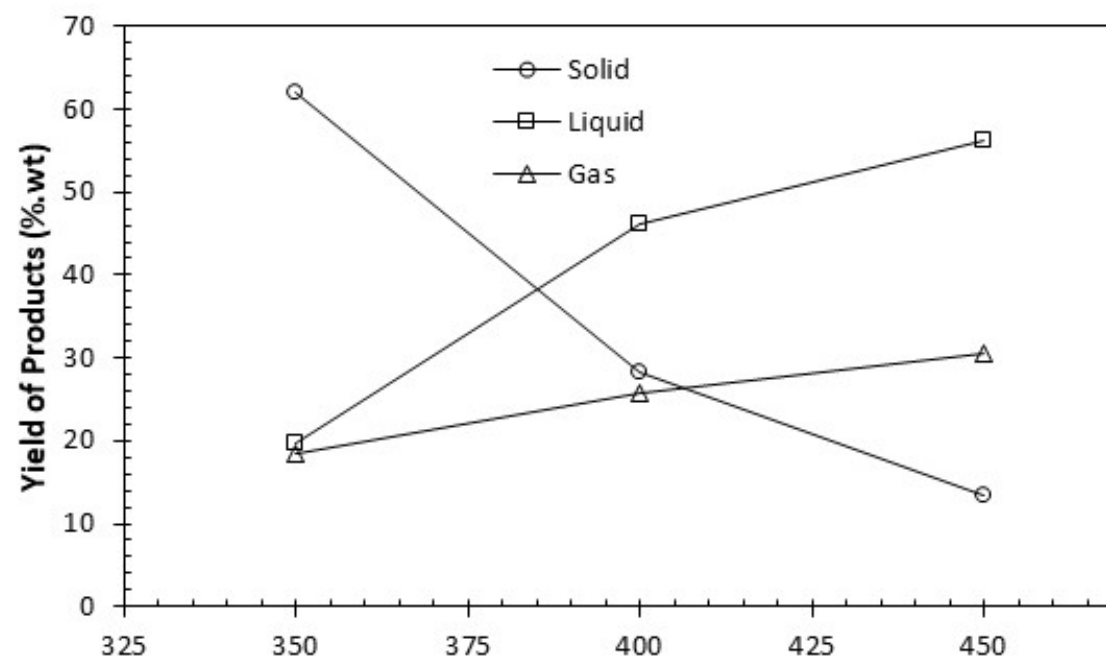

Figure 4: Product yield of hand phone case as a function of temperature.

Based on the results, plastic sample from hand phone case provided the highest yields of liquid oil compared with the other two samples. Thus, the measurement of the liquid oil heating value was carried out by using liquid oil product from thermolysis of hand phone case at $450^{\circ} \mathrm{C}$. The result showed that the heating value of liquid oil product was quite high at $39.25 \mathrm{MJ} \mathrm{kg}^{-1}$. This value corresponded to the heating values of pyrolysis oil obtained from various plastic materials which were in the range of $28-43 \mathrm{MJ} \mathrm{kg}^{-1} \cdot{ }^{14}$

\section{CONCLUSION}

Plastics from three types of e-waste were successfully characterised and treated under various temperatures in a microwave reactor to produce liquid oil. The results of elemental and proximate analyses showed that computer case and hand phone case contained high carbon and volatile material. These contents illustrated that they have the potential as a source of hydrocarbon fuels. Thermolysis process results reinforced the information in which both samples were capable of producing high enough liquid oil product. The highest yield of liquid oil was obtained from hand phone case sample while the lowest was from electrical cable. Thermolysis temperatures also played a major role in the e-waste decomposition process. In this work, optimum liquid oil yield of about $56.2 \mathrm{wt} \%$ was found at a reaction temperature of $450^{\circ} \mathrm{C}$. 


\section{ACKNOWLEDGEMENTS}

The authors gratefully acknowledge the Applied Research Grant (084/SP2H/LT/ DRPM/IV/2017) awarded by the Indonesia's Ministry of Research, Technology and Higher Education to carry out this work.

\section{REFERENCES}

1. Hanafi, J. et al. (2011). The prospects of managing WEEE in Indonesia. In Hesselbach, J. \& Herrmann, C. (Eds). Glocalized Solutions for Sustainability in Manufacturing: Proceedings of the 18th CIRP International Conference on Life Cycle Engineering, Technische Universität Braunschweig, Braunschweig, Germany, 2-4 May, Berlin, 492-496.

2. Schluep, M. et al. (2009). Recycling-from e-waste to resources: Sustainable innovation technology transfer industrial sector studies. New York: United Nations Environment Programme \& United Nations University.

3. Tue, N. M. et al. (2010). Accumulation of polychlorinated biphenyls and brominated flame retardants in breast milk from women living in Vietnamese e-waste recycling sites. Sci. Total Environ., 408(9), 2155-2162, https://doi. org/10.1016/j.scitotenv.2010.01.012.

4. Quan, C., Li, A. \& Gao, N. (2013). Combustion and pyrolysis of electronic waste: Thermogravimetric analysis and kinetic model. Proced. Environ. Sci., 18, 776-782, https://doi.org/10.1016/j.proenv.2013.04.104.

5. de Marco, I. et al. (2008). Pyrolysis of electrical and electronic wastes. J. Anal. Appl. Pyrol., 82(2), 179-183, https://doi.org/10.1016/j.jaap.2008.03.011.

6. Martinho, G. et al. (2012). Composition of plastics from waste electrical and electronic equipment (WEEE) by direct sampling. Waste Manage., 32(6), 1213-1217, https://doi.org/10.1016/j.wasman.2012.02.010.

7. Moltó, J. et al. (2009). Pyrolysis and combustion of electronic wastes. $J$. Anal. Appl. Pyrol., 84(1), 68-78, https://doi.org/10.1016/j.jaap.2008.10.023.

8. Salema, A. A. \& Ani, F. N. (2011). Microwave induced pyrolysis of oil palm biomass. Bioresour. Technol., 102(3), 3388-3395, https://doi.org/10.1016/j. biortech.2010.09.115.

9. Yin, C. (2012). Microwave-assisted pyrolysis of biomass for liquid biofuels production. Bioresour. Technol., 120, 273-284, https://doi.org/10.1016/j. biortech.2012.06.016. 
10. Zhixiao, Z., Bin, C. \& Xintian, Z. (2011). Microwave induced pyrolysis of bromine contained printed circuit board wastes. Paper presented at the Third International Conference on Measuring Technology and Mechatronics Automation, 6-7 January, 560-563, https://doi.org/10.1109/ icmtma.2011.427.

11. Anis, S. \& Zainal, Z. A. (2016). Effective conversion of biomass tar into fuel gases in a microwave reactor. AIP Conf. Proc., 1737(1), 060006, https://doi. org //10.1063/1.4949313.

12. Sun, J. et al. (2011). Recycling of waste printed circuit boards by microwaveinduced pyrolysis and featured mechanical processing. Ind. Eng. Chem. Res., 50(20), 11763-11769, https://doi.org/10.1021/ie2013407.

13. Maris, E. et al. (2015). Characterizing plastics originating from WEEE: A case study in France. Miner. Eng., 76, 28-37, https://doi.org/10.1016/j. mineng.2014.12.034.

14. Anuar Sharuddin, S. D. et al. (2016). A review on pyrolysis of plastic wastes. Energy Convers. Manage., 115, 308-326, https://doi.org/10.1016/j. enconman.2016.02.037.

15. Oh, S. C., Kwon, W.-T. \& Kim, S.-R. (2009). Dehydrochlorination characteristics of waste PVC wires by thermal decomposition. J. Ind. Eng. Chem., 15(3), 438-441, https://doi.org/10.1016/j.jiec.2008.11.010.

16. Hall, W. J. \& Williams, P. T. (2007). Analysis of products from the pyrolysis of plastics recovered from the commercial scale recycling of waste electrical and electronic equipment. J. Anal. Appl. Pyrol., 79(1), 375-386, https://doi. org/10.1016/j.jaap.2006.10.006. 